\title{
Intermodal system for mobility demand in the realities of the Russian Federation: reality and forecast
}

\author{
Nina Danilina ${ }^{a}$ \\ Moscow State University of Civil Engineering, 129337, Moscow, Russia
}

\begin{abstract}
The article talks about development of transport systems in context of sustainable urban development, transport problems, growing mobility demand and the way how to meet the needs of population of the Russian Federation by providing the right transport system adequate for the particular conditions of urban agglomeration being the reality of life in the Russian Federation. The author underlines the important role of passenger transport and makes all-around examination of the Intermodal Transport System, ITTU and Park\&Ride facilities as the basis on which the Russian Federation can build sustainable development of its cities.
\end{abstract}

\section{Introduction}

Recently, city development strategies have become the priorities of the Russian government. Extensive urbanization and rapid growth of urban territories naturally and permanently tend towards agglomerations and group settlements and generate constant intensification and complication of multiplied transport links, while traditional improvement efforts do not work. One of the most critical issues remains the problem of urban population mobility management, particularly during the peak period travel-times with the highest proportion of work trips. That's why innovative trends and instruments for modern urban transport system planning and engineering and organization are in urgent need to be chosen, investigated and implemented in a way to guarantee cities the sustainable provision of current and future demands in urban transportation.

\section{Sustainable development of urban transport system}

The main purpose of the urban transport system is balancing between meeting and managing public demands in traffic services using the infrastructure capacity of transport system. By judging results from program goals, it is considered the degree of compliance of transport services with the aims for city sustainable development and mobility of its inhabitants. The Town Planning Code of the Russian Federation determines the general direction of sustainable development of territories as "to ensure the implementation of urban development activities for security and favorable conditions of human life,

a Corresponding author: nina danilina@,mail.ru 
limiting the negative impact of economic and other activity on the generations" [1]. In the author's view, these conditions can be applied also to sustainable development of urban transport system integrally and to the public transport in particular. Thus, social, ecological and economic directions are the domains for urban transport development in the Russian Federation, which complies to three-dimension model of Sustainable Development Concept [2], where each of three aspects defines the consummation of basic transportation -function of the system.

The economic domain assumes that solutions in the sphere of transport services to increase urban mobility, accessibility, internal and external transport links are based on knowledge and objective regularities and will bring maximum economic efficiency in the development of the city and, as a consequence, the well-being of the citizens.

Social domain establishes the ensuring quality of life in the aspect satisfaction with population needs in traveling for various purposes. Public transport system offers a wide range of public services and their quality directly affects on the amount of their consumption and the mobility of the population in whole. Mobility right is one of the human and constitutional rights that encompasses the right of individuals to have an access within the territory of the city and the country. The essential conditions are not only the availability of public transport services, as well as high travel requirements to the security, comfort, warranty and planning possibility [3].

The ecological domain stresses the need to ensure environmental safety of the city ecosystem not only here and now, but also with the prospect for the future generations. Motor vehicles are a major source of harmful emissions into the atmosphere, noise, dust, vibration, which adversely affects both natural environment and health and psychological state of the person. The term "sustainability" in relation to the transport development encourages development of engineering, IT, design, spatial, technical and technological activities, including those at the stage of transport planning, up to the international environmental standards aimed at preserving the environment.

Synthesis of aspects defines vector of development of transport services and justifies for the adoption of a sustainable design solution

\section{Objectives for the sustainable development of public urban transport system}

World experience of sustainable transport systems planning and design marks the need to ensure unimpeded access to any public urban area for all social groups of population and, moreover, to provide the most easy, convenient and safe trip regardless of its purposes [4]. Traditionally, difficulty accessing urban area is measured as time spent on the trip, which can be used as the main quantitative indicator of public transport system development level. This approach permits to judge the sustainability level of public transportation by its ability to offer minimal difficulty trips conditions, regardless of the placement of residential areas within urban areas. As a rule, the urban population grows at a faster rate than the expanding of road network and development of public transport systems. This causes the imbalance between the level of public demand for transport services and potential capabilities of the transport systems. Therefore, the use of the passenger public transport and in particular high speed types of public transport is considered to be the most rational and promising way to trip as it does not depend on traffic conditions on the road network.

The policy of priority development of high-speed modes is fully consistent with the concept of sustainable development [5]. It allows meet the demands of the population mobility with maximum efficiency in land use and transport resources and much less pollution than road transport. The world practice witnesses that formation of comfortable, fast and safe system resolves the problem of public transportation and also generates further 
urban development in areas of accessibility to its route network stations. There are clearly expressed relations between residential density, travel patterns and distance to publictransport facilities, for example to the main station of high-speed public transport system (Figure 1). Closer is the station, greater is number of the buildings, residential density and number of people eager to prefer passenger transport to trip. Farther is the station, more are the trips by means of private vehicles, due to the increasing difficulty of passenger transport trip. The problem of equitable access of all social groups of population to urban areas and transport infrastructure is most acute in major cities with developed suburbs and in agglomerations characterized by peculiar spatial scale resettlement forms. So the choice of such form of public transport system that balances the difficulty and functional efficiency of the trip regardless of the distance to the public transit stations becomes particularly important.

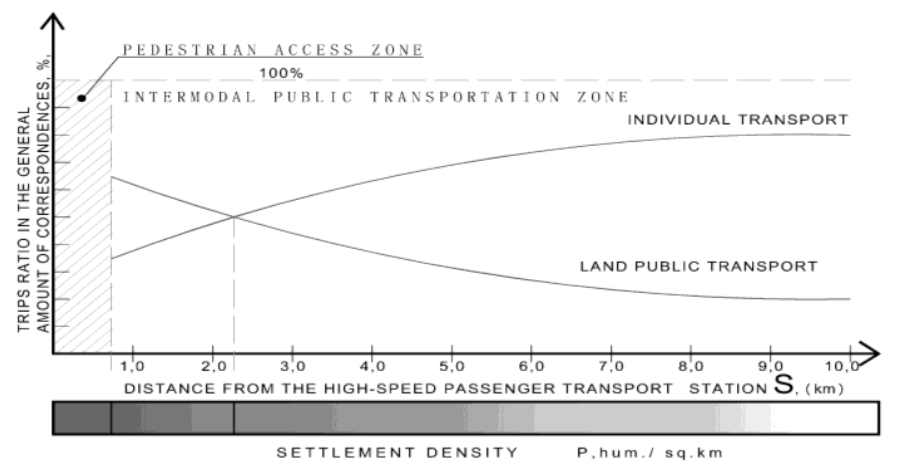

Fig. 1. Relationships between urban density and travel patterns.

\section{Choosing right public transport system for the Russian federation}

Urban agglomeration is the reality of life in the Russian Federation. Typically, structure and forms of organization of transport system in Russian cities are defined by the number of people living on their territory. Threshold population of the city over 500,000 people suggests priority given to off-street modes to be implemented as the framework of public transport. The cities with population less than 1 million prefer LRT systems or bus rapid transit (BRT systems); in cities with population of more than 1 million it is considered the necessity of construction conventional underground metropolitan or S-Bahn with greater carrying capacity. High-speed modes of transport as part of the urban transportation system become concentration points of passenger load, since, as a rule, they connect main residential areas of the city and its focuses of labor gravity. Due to natural self-regulating urban development processes, vital activity of population centralizes in areas of accessibility to high-speed modes of transport resulting in the development of residential and public functions of adjacent territories.

Current trends in the public transportation enable not only quantitative and qualitative development of actual passenger transport, but of new modes of passenger transportation. According to the author, the most suitable to Russian realities way to meet the mobility demand is the adoption of intermodal communication supported by the system of Intermodal Transport Transit Hubs (ITTH) that already has experienced implementation in the Russian Federation [6]. For example, Moscow Industry Development Scheme of ITTH up to the year 2020 envisages the implementation of 255 ITTH on the territory of the Moscow agglomeration based on subway and railway systems [7]. Official web site 
of the Committee for transport infrastructure development informs that it has been already decided to construct 11 ITTH in St. Petersburg and that the best pioneer practices of the major cities will be implemented in other developing cities in Russia. In view of such promising development prospects, it seems possible to propose the original Model that forecasts the potential of ITTH and suggests its most efficient and effective use [8].

Research and analysis of ITTH global experience in urban conditions similar to those of the Russian Federation, allows to suggest the development of TPU as urban and suburban focal points with maximum passengers concentration, places of attraction for public and private road transport. Access control to ITTH becomes a demand for managing centripetal process of traffic and pedestrian flows [9]. The main objective is to satisfy mobility demand providing opportunities for free use of transport services offered by the ITTH for people living around and within its zone of influence. It is possible to identify three main areas distinguished by the distance to the station and access mode to ITTH (Figure 1, 2), such as:

- $\mathrm{R}=700 \mathrm{~m}-$ pedestrian access area;

- $\mathrm{R}=2200 \mathrm{~m}-$ public transport access area with high proportion of passenger land transport modes users and

- $\mathrm{R}>2200 \mathrm{~m}$ - individual transport access area with constantly increasing proportion of private vehicles used in direct ratio to the distance from ITTH (authors' study indicates radius about $10-15 \mathrm{~km}$.)

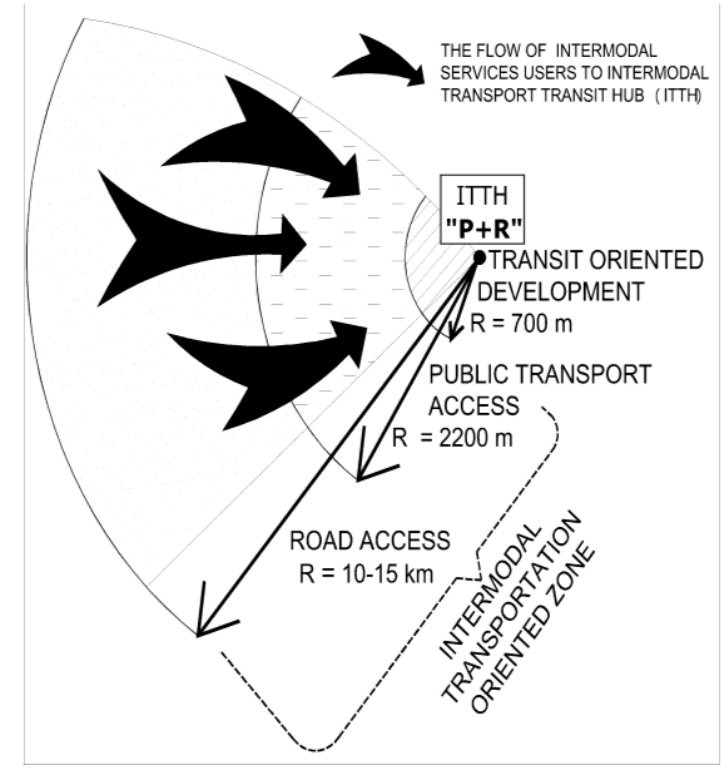

Figure 2. Access conditions to Intermodal Transport Transit Hub.

Besides the distance to the station, each zone is characterized by speed and time of travel time to ITTH both depending on type of the transport used. Under the highest level of development of the system of transport services shall be understood the state of things when a trip between a point $I$ located within $n$-th influenced zone and a point $J$ located in ITTH by any mode of transport including walking, driving and public transit, is made by the shortest route $S_{n}$ with the highest speed $V_{n}$ possible for the $L$ mode of transport, and the less overhead costs $T_{n}$, for $L$ mode of transport. If the time $\mathrm{T}$ for the part of the trip made after taking high-speed mode of transport assume as a constant value for all groups 
of passengers, then the very small amount of time to commit travel is determined by mathematical expression:

$$
\bar{T}_{I J}^{L}=\min \left\{\begin{array}{c}
T+S_{1}^{L} / V_{1}+T_{1}^{L} \\
T+S_{2}^{L} / V_{2}+T_{2}^{L} \\
T+S_{3}^{L} / V_{3}+T_{3}^{L}
\end{array}\right\}, \text { [minutes] }
$$

The value of the maximum level of development of the system will be influenced by technical characteristics of vehicles and the expected characteristics of the trips, such as speed and overhead time defined by existing or planned urban transport conditions.

Let's consider the specific features and peculiar requirement for transport service of each zone.

The zone of pedestrian accessibility to ITTH bounded by the radius $\mathrm{R}=700 \mathrm{~m}$ is the area of Transit oriented development policy implementation [10]. TOD policy is internationally recognized as the best way of public transport organization in compliance with the principles of sustainable development in all respects. Walking distance from the area of high-speed passenger transport facilities and stations means minimum need and, as a consequence, minimal time and money trip costs. Transport independence solves a complex of everyday problems and directly affects the quality of life and ecological purity of environment. Economically, territories adjacent to ITTH have strong investment appeal. Transit oriented development areas within ITTH walking distance provide for a diverse and intensive mix of residential, commercial, public, administrative and cultural land users and are characterized usually by high density and high rise building. Sustainable public transport system in such zones requires a dense pedestrian communication network connecting ITTN with places of residence or places of employment in the shortest way and functioning also as a public space. In the absence of urban resources to construct a system of high-speed passenger transport providing the density necessary to cover the whole territory of the city by walking zones in pedestrian access to ITTH, there are alternative ways of organizing transport services, focused on the use of one or another type of transport, in particular, to reach the ITTH.

From a distance of more than 700 meters, pedestrian flow begins to wane in proportion to the difficulty accessing ITTH. When human speed is $4.5 \mathrm{~km} / \mathrm{h}$, time spent on foot movement begins to exceed the psychological level of 10 minutes, that stimulates the choice in favor of motorized transport modes, so preferences of ITTH users shift towards intermodal trips. Intermodal trip is a combination of several types (modes) of transport, a transfer from one to the other is made in ITTH. There are two main ways of committing the intermodal trip characterized by two basic types of transfer to a highspeed type of transport from public transport modes or from a private car. Researches confirm that the flow capacity of each type users depends on the distance from ITTH. Let's consider for example two main zones with most characteristic features:

a. Zone situated at distance $\mathrm{R}=2200 \mathrm{~m}$., requires about $20-25$ minutes trip to ITTH by passenger transport, taking into account overheads, at an average speed of public transport about $30 \mathrm{~km} / \mathrm{h}$. These rates do not exceed the psychological threshold and allow increasing the number of users arriving to ITTH by terrestrial mods of passenger transport while ensuring unimpeded access to terrestrial passenger transport services and meeting the following requirements: 
- requirements for rolling stock: carrying capacity and quality of the rolling stock shall comply with the level of demand from the population and provide a comfortable and safe travelling conditions;

- traffic requirements: traffic frequency, length of routes, speed must ensure the least possible overhead time waiting. A prerequisite is a clear line route schedule.

- requirements for the highway-road network: priority conditions for passenger transport in ITTH; local events in the area of stopping points and on the route;

- requirement for ITTU: arrangement of boarding-landing points, minimizing overhead costs time to enter the TPU and change process itself;

- travel information requirements: the existence of placards with routes, waiting time and related information, including free access to online services.

b.Zone situated at distance $\mathrm{R}>2200 \mathrm{~m}$, is the territory where a personal car becomes the predominant mode of transportation due to the high difficulty of the trip to ITTH. As the psychological threshold of time expenses for intermodal trip must not exceed 20 25 minutes, so this area is restricted by a maximum radius of $10-15 \mathrm{~km}$, taking into account the time overhead costs, at an average speed of road traffic $\mathrm{km} / \mathrm{h}$. In this case, the promotion of intermodal travel of "private car-passenger transport» type requires along with controlled-access street network and highway access managing - especially during peak hours - the accommodation of Park@Ride facilities [11].

World experience of Park\&Ride facilities attests to the relevance of this service to that part of the population, that prefers private car to passenger transport. During the morning peak hours, when the street network is overwhelmed, the need for planning and high difficulty private car trip shifts the priority in favor of speed passenger transport, especially when the direction of its work duplicates the driver's route. Park\&Ride services located in ITTU is the link between street network and passenger transport which allows the owner to leave the car for a long time in safe environment. Integration of Park\&Ride in ITTU composition - unified system of pedestrian communications, well organized transit, common payment and cheap rate system - are powerful incentives to use the service and, as a consequence, to increase the number of intermodal trips.

\section{Conclusions}

Knowledge and experience accumulated allow the author to conclude that Intermodal Transport System - of the number of innovation systems proven by international and Russian practice - fits up the Russian conditions of global urbanization and constant growth of private cars. ITTU and Park\&Ride facilities create basis for sustainable development of Russian urban territories in spite of the fact that the intermodal trip time today remains exceeds the normative values. The implementation of Intermodal Transport System in Russia will meet the growing economic and social mobility needs, will provide equal mobility opportunities for all social groups, increase the attractiveness of passenger transport modes and reduce human impacts on the environment. That is, to improve the quality of urban environment and the quality of life of the population.

\section{References}

1. The town-planning code of the Russian Federation (by the UDC) of 29 December 2004 No. 190-FZ, http://base.garant.ru/12138258/\#ixzz41gbpboki

2. E.V. Sherbina, N.V. Danilina, D.N. Vlasov, Jour. of Applied Engineering Research, 10-22, 43131-43138 (2015)

3. E.V. Sherbina, E.V. Gorbenkova, Scientific Review, 9, 128-131 (2013) 
4. E.V Sherbina, M. Afonina, Experience in application of antierosion geo-compositional systems for sustainable development of recreational and sports facilities, 159-164 (2014)

5. Sustainable planning and design of urban transportation system: national report of OON Habitat Programme, http://www.unhabitat.ru/ru/publications/reports/reports (2013)

6. E.V. Sherbina, D.N. Vlasov, Architecture and construction of Russia, 6, 2 (2013)

7. Urban planning project of public transit transport hubs formation, http:/www.genplan.ru/

8. D.N. Vlasov, Academy. Architecture and construction, 3, 86-89 (2013)

9. D.N. Vlasov, Reducing the burden on the road network of Central planning zone from intercity transit of motor transport (on the example of Moscow): the dissertation of candidate of technical Sciences, (1999)

10. D.N. Vlasov, Architecture and construction of Russia, 8 (212), 20-29 (2015)

11. N.V. Danilina, Scientific-methodical bases of formation of system of "Park and ride" Parking areas in the largest cities: the example of the city of Moscow: the dissertation ... of candidate of technical Sciences (2012) 